\title{
Genetic variation in KSHV encoded microRNAs affects microRNA expression and is associated with multicentric Castleman's disease risk
}

\author{
Vickie Marshall ${ }^{1}$, Alex Ray ${ }^{1}$, Soo-Jin Han², Thomas Uldrick ${ }^{3}$ Eugene Barsov ${ }^{4}$, Octavio Quinones ${ }^{5}$, Robert Leighty ${ }^{5}$, \\ Nazzarena Labo ${ }^{1}$, Kathy Wyvill ${ }^{3}$, Karen Aleman ${ }^{3}$, Mark N Polizzotto ${ }^{3}$, Richard F Little ${ }^{3}$, David Ott ${ }^{4}$, Robert Yarchoan ${ }^{3}$, \\ Rolf Renne ${ }^{2}$, Denise Whitby ${ }^{1 *}$
}

From 13th International Conference on Malignancies in AIDS and Other Acquired Immunodeficiencies (ICMAOI)

Bethesda, MD, USA. 7-8 November 2011

Kaposi sarcoma-associated herpesvirus (KSHV) encodes 12 pre-microRNAs which potentially yield 25 mature microRNAs and have been shown to play prominent roles in the viral lifecycle including maintaining viral latency, evading the host immune response, and controlling lytic replication. We previously reported phylogenetic analysis of the microRNA-coding region of KSHV from Kaposi sarcoma (KS), primary effusion lymphoma (PEL), and multicentric Castleman disease (MCD) patients. We showed a high level of conservation for most sequences, but also a divergent cluster of $5 \mathrm{KSHV}$ sequences including 2 from MCD patients [1]. We additionally observed single nucleotide polymorphisms (SNP) in the sequence of KSHV encoded mature and pre-miRNAs from clinical samples including a SNP in mir-K12-5 reported to result in increased expression of the mature miRNA [2].

To determine whether SNPs in other KSHV encoded miRNAs resulted in differences in miRNA processing and expression we used four complimentary approaches. Analysis of KSHV miRNA expression levels in PEL cell lines using custom ABI real time qPCR assays showed differential expression that correlates with sequence. Lentiviral vectors constructed to express wild type and variant pre-miRNAs were transduced into $293 \mathrm{~T}$ cells to make stably expressing cell lines. miRNA expression was assessed using custom ABI real time qPCR assays. Luciferase reporter assays were performed following transient

\footnotetext{
* Correspondence: denise.whitby@nih.gov

'Viral Oncology Section, AIDS and Cancer Virus Program, SAIC-Frederick,

National Cancer Institute (NCl)-Frederick, Frederick, MD, USA

Full list of author information is available at the end of the article
}

transfections of each miRNA. In addition, in vitro maturation assays were performed to assess differences in Drosha/DGCR8 and Dicer cleavage between wild type and variant pre-miRNAs. Our results indicate that polymorphisms within the pre-miRNA sequence can cause subtle expression differences as in the case of KSHV miR-K12-6 or more profound changes as observed in miR-K12-5. Our data clearly shows that SNPs can affect pre-miRNA processing resulting in changes in mature miRNA expression levels.

To extend our studies on miRNA variation in MCD patients, KSHV miRNA sequences from $23 \mathrm{MCD}$ patients and 7 patients with a newly described KSHVassociated inflammatory cytokine syndrome (KICS) were examined by amplification, cloning, and sequencing of a 646-bp fragment of K12/T0.7 encoding miRNA-K12-10 and miRNA-K12-12 and a 2.8-kbp fragment containing the remaining 10 pre-microRNAs. Phylogenetic analysis showed a distinct variant cluster consisting exclusively of MCD and KICS patients in all trees. Pearson's chisquared analysis revealed 40 single nucleotide polymorphisms (SNPs) at various loci were significantly associated with MCD and KICS risk. Additionally, cluster analysis of these SNPs generated several combinations of three SNPs as putative indicators of MCD and KICS risk. Taken together, these findings show that MCD and KICS patients frequently have unusual KSHV microRNA sequences and suggest association between the observed sequence variation and risk of MCD and KICS. 


\section{Author details}

'Viral Oncology Section, AIDS and Cancer Virus Program, SAIC-Frederick, National Cancer Institute (NCI)-Frederick, Frederick, MD, USA. ${ }^{2}$ Department of Molecular Genetics and Microbiology, University of Florida, Gainesville, FL, USA. ${ }^{3} \mathrm{HIV}$ and AIDS Malignancy Branch, NCI, Bethesda, MD, USA. ${ }^{4}$ Retrovirus Assembly Laboratory, AIDS and Cancer Virus Program, SAIC-Frederick, Frederick, MD, USA. ${ }^{5}$ Data Management Services, Inc, NCl-Frederick, Frederick, MD, USA.

Published: 19 April 2012

\section{References}

1. Marshall V, et al: Conservation of virally encoded microRNAs in Kaposi Sarcoma-Associated Herpesvirus in primary effusion lymphoma cells lines and in patients with Kaposi sarcoma or multicentric Castleman disease. JID 2007, 195(5):645-59.

2. Gottwein $E$, et al: A novel assay for viral microRNA function identifies a single nucleotide polymorphism that affects Drosha processing. J Virol 2006, 80(11):5321-6.

doi:10.1186/1750-9378-7-S1-05

Cite this article as: Marshall et al: Genetic variation in KSHV encoded microRNAs affects microRNA expression and is associated with multicentric Castleman's disease risk. Infectious Agents and Cancer 2012 7(Suppl 1):05.

\section{Submit your next manuscript to BioMed Central} and take full advantage of:

- Convenient online submission

- Thorough peer review

- No space constraints or color figure charges

- Immediate publication on acceptance

- Inclusion in PubMed, CAS, Scopus and Google Scholar

- Research which is freely available for redistribution

Submit your manuscript at www.biomedcentral.com/submit 